\title{
Numerical Model with Finite Differences Approach for CRS Consolidation Test
}

\author{
Abderrahmane Henniche ${ }^{1, *}$, Smain Belkacemi ${ }^{2}$ \\ ${ }^{1}$ Department of Civil Engineering, University of Medea, Medea, Algeria \\ ${ }^{2}$ Department of Civil Engineering, Ecole Nationale Polytechnique, Algiers, Algeria
}

Email address:

henniche.Ictp $a$ yahoo.fr (A. Henniche), smain.belkacemi $a$ g.enp.edu.dz (S. Belkacemi)

${ }^{*}$ Corresponding author

To cite this article:

Abderrahmane Henniche, Smain Belkacemi. Numerical Model with Finite Differences Approach for CRS Consolidation Test. Engineering Science. Vol. 3, No. 3, 2018, pp. 26-35. doi: 10.11648/j.es.20180303.11

Received: November 13, 2018; Accepted: December 5, 2018; Published: January 3, 2019

\begin{abstract}
The Constant Rate of Strain (CRS) consolidation test is extensively used in last time to estimate the settlement of clayey soils in many geotechnical laboratories. Different theoretical solutions and numerical models have been developed to estimate consolidation parameters from CRS consolidation test data, and investigate the strain rate effect on the CRS consolidation results. In this study, a new numerical model is developed to simulate CRS consolidation test for small and large strain conditions and for both linear and nonlinear soils. This numerical model is based on the solution of Terzaghi's classical consolidation equation by finite differences approach, with taking into account the variation of sample height with test time. Results of this numerical model indicate that applied vertical load at the top boundary of sample and excess pore pressure at its base are dependent on the applied strain rate. Evaluation of the consolidation parameters from numerical results of this model with small and large theoretical solutions shows excellent agreement between all methods in small strain level, and when large strain conditions are reached only use of large strain theories can produce good convergence with model results. However, when great strain rates (approximately $\beta \geq 0.1$ ) are applied, a significant error can be observed in consolidation parameters calculation by using both small and large solutions. Finally, simulation of some experimental CRS tests reported in literature with this numerical model provides comparable consolidation parameters to those evaluated from the experimental CRS tests data.
\end{abstract}

Keywords: Consolidation, CRS Test, Compressibility, Strain Rate, Numerical Model, Consolidation Parameters

\section{Introduction}

The Constant Rate of Strain consolidation test (CRS test) became in the last decades as an alternative procedure to the standard consolidation test (IL test) to evaluate the consolidation properties of clayey soils in many countries. The CRS consolidation test, comparatively to the standard consolidation test, can be completed in a reduced time (one to two days) for large range of soils, and produces continuous responses in particular the compressibility curve. The CRS consolidation test was developed for the first time by Hamilton and Crawford (1959) [1] to overcome some disadvantages of standard consolidation test. The main CRS consolidation theories were further developed by Smith and Wahls (1969) [2] and Wissa et al (1971) [3], based on assumptions similar to Terzaghi's ordinary consolidation theory with small strain conditions. Subsequently, several studies based on large strain conditions, have been conducted [4-6] to take into account the continuous nature of CRS test with important total stain levels [7, 8]. Furthermore, many other studies $[5,9,10]$ considered that the small strain theory can be only used to simulate the CRS consolidation for the small strain levels, and it produces significant error for large strain levels. In all cases, consolidation parameters obtained by CRS consolidation tests are dependent on the applied strain rates [2, 7, 11-16], and many criteria have been proposed by authors to select adequate strain rates for CRS tests $[2,3,5,17]$.

In this paper, a new numerical model based on finite differences approach is built to simulate the CRS consolidation test by using iteratively, during successive 
small time steps, the Terzaghi's linear one-dimensional consolidation theory. The coefficient of consolidation $c_{v}$ is assumed to be constant during all the consolidation process, but the height of sample $h$, effective stress $\sigma_{v}$, and void ratio $e$, are varying with time. The creep and self-weight effects are ignored. To take into account the effect of compressibility, both linear and nonlinear soils are considered. The results of model are shown and then used to evaluate the consolidation parameters $\left(c_{v}\right.$ and $\left.k_{v}\right)$ by using small and large strain theories, which permits to check the convergence between model results and the large strain theories. The results of some experimental works are also used to check the ability of this numerical model to produce consolidation parameters $\left(c_{v}\right.$ and $\left.k_{v}\right)$ comparable to those evaluated during experimental CRS tests.

\section{Model Structure}

In the CRS consolidation test, a soil sample with an initial thickness of $H_{0}$, is contained within a consolidation cell and deformed at constant strain rate $r$. A vertical load $\Delta \sigma_{v}$ is applied at the drained top side of sample, and the excess pore pressure $\Delta u_{H}$ is measured at the undrained bottom side.

In this model, at any time $t$ of CRS test, the height of sample $h$ is divided into $n$ soil elements with equal thicknesses $\Delta z$. The vertical depth $z(t)$, and the number $j$ of each boundary between two successive elements are defined positive downward from the top side. At each time $t$, the height of sample $h(t)$ is:

$$
h(t)=H_{0}(1-r t)
$$

And the thickness of each soil element $\Delta z(t)$ is:

$$
\Delta z(t)=h(t) / n
$$

With $n$ is the number of soil sample elements.

The Terzaghi's linear one-dimensional consolidation equation is used iteratively during successive time steps $\Delta t$, to simulate the continuous loading of CRS consolidation test. The parameters necessary to calculations are updated at the beginning of each time step. The Terzaghi's consolidation theory assumes essentially the soil sample is homogeneous and saturated; theDarcy's law is valid and the coefficient of consolidation $c_{v}$ is constant during all the consolidation process.

The Terzaghi's linear one-dimensional consolidation equation, for continuous loading, is written as:

$$
c_{v} \frac{\partial^{2} u}{\partial z^{2}}=\frac{\partial u}{\partial t}+\frac{\partial\left(\Delta \sigma_{v}\right)}{\partial t}
$$

With:

$c_{v}$ is the coefficient of consolidation of soil.

$u$ is the excess of pore pressure at vertical depth $z$ and time $t$.

$\Delta \sigma_{v}$ is the applied vertical load.

During CRS test, the sample thickness is variable, and use of Terzaghi's consolidation equation leads at every time step $\Delta t$, to neglect the excess pore pressure values of soil part deformed between two successive times $t$ and $t+\Delta t$ (figure1a). However, although the excess pore water pressure is very small in the neglected part of soil near the drained face, the use of Terzaghi's consolidation equation with normalized parameters permits to take in consideration the totality of sample thickness in calculations (figure 1b).

Let $u_{r}, t_{r}$ and $z_{r}$ be any arbitrary reference excess pore water pressure, time, and vertical depth, respectively. From these, the following dimensionless terms can be defined [18]:

Dimensionless excess pore water pressure $\bar{u}=u / u_{r}$ Dimensionless applied vertical load $\Delta \overline{\sigma_{v}}=\Delta \sigma_{v} / u_{r}$ Dimensionless time $\bar{t}=t / t_{r}$ and

Dimensionless vertical depth $\bar{z}=z / z_{r}$
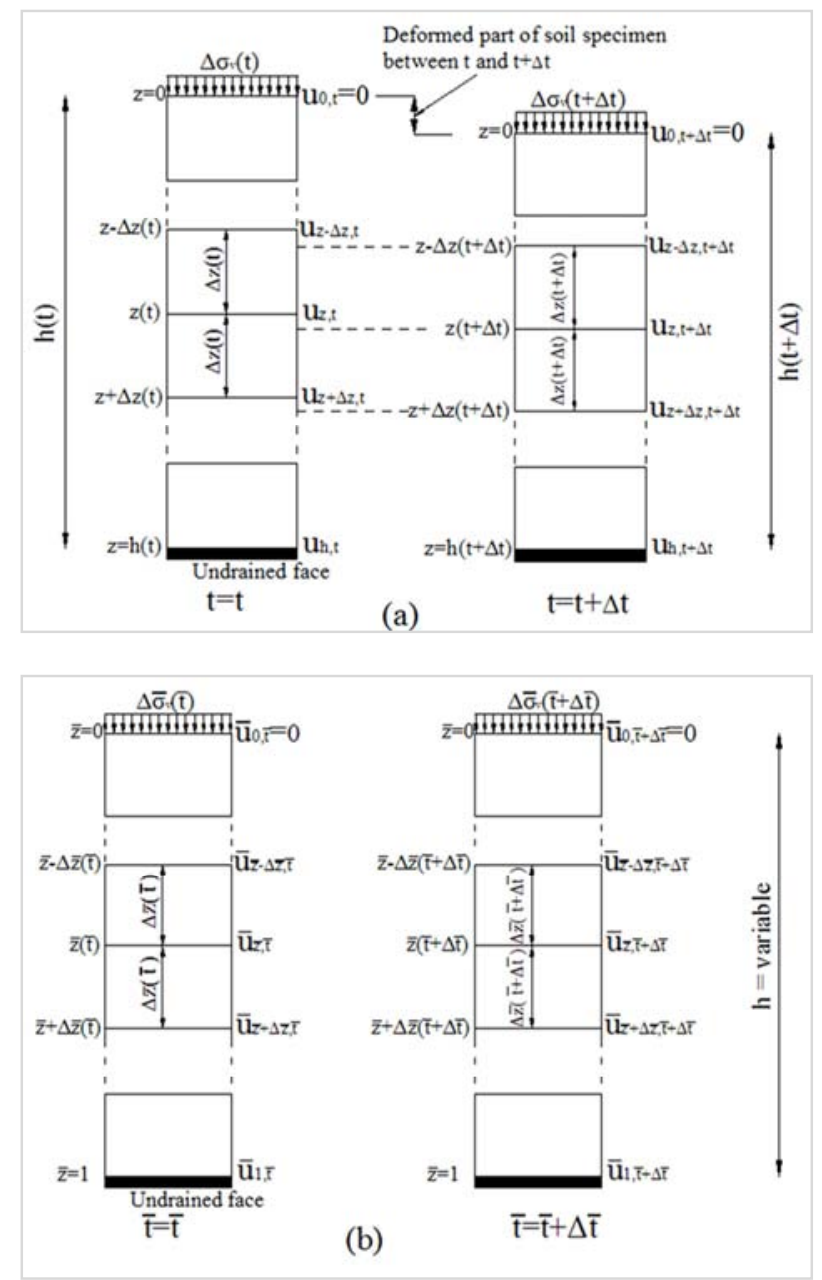

Figure 1. Numerical solution of consolidation with: a) Dimensional parameters; b) Normalized parameters.

The Terzaghi's linear one-dimensional consolidation equation becomes:

$$
c_{v} \frac{u_{r}}{z_{r}^{2}} \frac{\partial^{2} \bar{u}}{\partial \bar{z}^{2}}=\frac{u_{r}}{t_{r}}\left(\frac{\partial \bar{u}}{\partial \bar{t}}+\frac{\partial \Delta \overline{\sigma_{v}}}{\partial \bar{t}}\right)
$$


The arbitrary reference time can be considered equal to: $t_{r}=z_{r}^{2} / c_{v}$, then equation (4) will be of the form:

$$
\frac{\partial^{2} \bar{u}}{\partial \bar{z}^{-2}}=\left(\frac{\partial \bar{u}}{\partial \bar{t}}+\frac{\partial \Delta \overline{\sigma_{v}}}{\partial \bar{t}}\right)
$$

The left-hand and right-hand sides of equation (5) can be written as:

$$
\frac{\partial^{2} \bar{u}}{\partial \bar{z}^{-2}}=\frac{1}{(\Delta \bar{z})^{2}}\left(\bar{u}_{\bar{z}+\Delta \bar{z}, \bar{t}}+\bar{u}_{\bar{z}-\Delta \bar{z}, \bar{t}}-2 \bar{u}_{\bar{z}, \bar{t}}\right)
$$

Where $\bar{u}_{\bar{z}+\Delta \bar{z}, \bar{t}}, \bar{u}_{\bar{z}-\Delta \bar{z}, \bar{t}}$ and $\bar{u}_{\bar{z}, \bar{t}}$ are the dimensionless pore water pressures at dimensionless time $\bar{t}$ and at dimensionless depths $\bar{z}+\Delta \bar{z}, \bar{z}-\Delta \bar{z}$ and $\bar{z}$ respectively.

$$
\frac{\partial \bar{u}}{\partial \bar{t}}=\frac{1}{\Delta \bar{t}}\left(\bar{u}_{\bar{z}, \bar{t}+\Delta \bar{t}}-\bar{u}_{\bar{z}, \bar{t}}\right)
$$

Where $\bar{u}_{\bar{z}, \bar{t}+\Delta \bar{t}}$ and $\bar{u}_{\bar{z}, \bar{i}}$ are the dimensionless pore water pressures at dimensionless depth $\bar{z}$ and at dimensionless times $\bar{t}+\Delta \bar{t}$ and $\bar{t}$ respectively.

$$
\frac{\partial\left(\Delta \overline{\sigma_{v}}\right)}{\partial \bar{t}}=\frac{1}{\Delta \bar{t}}\left(\Delta \bar{\sigma}_{v, \bar{t}+\Delta \bar{t}}-\Delta \bar{\sigma}_{v, \bar{t}}\right)
$$

Where $\Delta \bar{\sigma}_{v, \bar{t}+\Delta \bar{t}}$ and $\Delta \bar{\sigma}_{v, \bar{t}}$ are the dimensionless applied vertical load values at times $\bar{t}+\Delta \bar{t}$ and $\bar{t}$ respectively.

Substituting equations (6), (7) and (8) in equation (5), gives:

$$
\begin{gathered}
\bar{u}_{\bar{z}, \bar{t}+\Delta \bar{t}}=\frac{\overline{\Delta t}}{(\Delta \bar{z})^{2}}\left(\bar{u}_{\bar{z}+\Delta \bar{z}, \bar{t}}+\bar{u}_{\bar{z}-\Delta \bar{z}, \bar{t}}-2 \bar{u}_{\bar{z}, \bar{t}}\right)+\bar{u}_{\bar{z}, \bar{t}}+I \\
I=\left(\overline{\Delta \sigma}_{v, \bar{t}+\Delta \bar{t}}-\Delta \bar{\sigma}_{v, \bar{t}}\right)
\end{gathered}
$$

For equation (9) converges, $\Delta \bar{t}$ and $\Delta \bar{z}$ must be chosen such that: $\Delta \bar{t} /(\Delta \bar{z})^{2}<0.5$

To take into account the sample height at every time $t$ of CRS test, the arbitrary reference depth $z_{r}$ is taken equal to: $z_{r}=h(t)$

$$
\frac{\Delta \bar{t}}{(\Delta \bar{z})^{2}}=\frac{\Delta t \cdot c_{v} \cdot n^{2}}{(h(t))^{2}}
$$

For undrained face of specimen $(z=H): \bar{u}_{\bar{z}+\Delta \bar{z}, \bar{t}}=\bar{u}_{\bar{z}-\Delta \bar{z}, \bar{t}}$, and equation (9) becomes:

$$
\bar{u}_{\bar{z}, \bar{t}+\Delta \bar{t}}=\frac{\Delta \bar{t}}{(\Delta \bar{z})^{2}}\left(2 \bar{u}_{\bar{z}-\Delta \bar{z}, \bar{t}}-2 \bar{u}_{\bar{z}, \bar{t}}\right)+\bar{u}_{\bar{z}, \bar{t}}+I
$$

The pore water pressure at any dimensionless depth $\bar{z}$ and at dimensionless time $\bar{t}+\Delta \bar{t}$ is:

$$
u_{\bar{z}, \bar{t}+\Delta \bar{t}}=\bar{u}_{\bar{z}, \bar{t}+\Delta \bar{t}} \times u_{r}
$$

The value of $\Delta t$ is evaluated versus a preset final deformation of sample $\varepsilon_{f}$. If pore water pressure converges for $\Delta t$ and $\Delta z$ chosen from $\varepsilon_{f}$, it converges automatically during all the test duration ( $\varepsilon<\varepsilon_{f}$ ).

The applied vertical load is evaluated at any time during CRS test from the specimen deformation (or void ratio diminution):

$$
e(t)=e_{0}-\left(1+e_{0}\right) \cdot r t
$$

With $e_{0}$ is the initial void ratio of sample, and $e(t)$ is the void ratio value $e$ at time $t$.

For linear soil $\left(a_{v}=\right.$ constant $)$ :

$$
\begin{gathered}
e(t)=e_{0}-a_{v}\left(\sigma_{v}^{\prime}-\sigma_{v 0}^{\prime}\right) \\
\sigma_{v}^{\prime}(t)=\sigma_{v 0}^{\prime}+\frac{\left(1+e_{0}\right) r t}{a_{v}}
\end{gathered}
$$

With $\sigma_{v 0}^{\prime}$ is the initial effective vertical stress that considered at equilibrium with initial void ratio $e_{0}$, and $\sigma_{v}^{\prime}(t)$ is the value of effective vertical stress $\sigma_{v}^{\prime}$ at time $t$.

$a_{v}$ is the coefficient of compressibility that considered constant for linear soil.

For nonlinear soil $\left(c_{c}=\right.$ constant $)$ :

$$
\begin{aligned}
& e(t)=e_{0}-c_{c} \log \left(\sigma_{v}^{\prime} / \sigma_{v 0}^{\prime}\right) \\
& \sigma_{v}^{\prime}(t)=\sigma_{v 0} \times 10^{\left(\left(1+e_{0}\right) r t / c_{c}\right)}
\end{aligned}
$$

With $c_{c}$ is the compression index that considered constant for nonlinear soil.

At every time during CRS test, effective stress hypothesis of Terzaghi is considered valid:

$$
\Delta \sigma_{v}(t)=\Delta \sigma_{v}^{\prime}(t)+\Delta u_{\text {avg }}(t)
$$

For linear soil $\left(a_{v}=\right.$ constant $)$ :

$$
\begin{gathered}
\Delta \sigma_{v}^{\prime}(t)=\sigma_{v}^{\prime}(t)-\sigma_{v 0}^{\prime}=\frac{\left(1+e_{0}\right) \cdot r t}{a_{v}} \\
\Delta \sigma_{v}(t)=\frac{\left(1+e_{0}\right) r t}{a_{v}}+\Delta u_{\text {avg }}(t)
\end{gathered}
$$

For nonlinear soil $\left(c_{c}=\right.$ constant $)$ : 


$$
\begin{gathered}
\Delta \sigma_{v}^{\prime}(t)=\sigma_{v 0}^{\prime} \times\left(10^{\frac{\left(1+e_{0}\right) r t}{C_{c}}}-1\right) \\
\Delta \sigma_{v}(t)=\sigma_{v 0}^{\prime} \times\left(10^{\frac{\left(1+e_{0}\right) r t}{C_{c}}}-1\right)+\Delta u_{a v g}(t)
\end{gathered}
$$

The average pore water pressure excess through the specimen at time $t$ is equal to:

$$
\Delta u_{\text {avg }}(t)=\frac{1}{H} \int_{0}^{H} u_{z, t} \cdot d z
$$

Equation (24) is numerically evaluated by the trapezoidal integration method.

To evaluate the applied vertical load at any time $t+\Delta t$, and because the value of $\Delta u_{\text {avg }}(t+\Delta t)$ is unknown, calculations at the beginning of each time step can start with the known value of $\Delta u_{\text {avg }}(t)$ estimated at time $t$. A primary value of $\Delta \sigma_{v}(t+\Delta t)$ is evaluated (Equation.19) and then a primary value of $\Delta u_{\text {avg }}(t+\Delta t)$ is also evaluated (Equation.13), and this process is repeated during each iteration until difference between two values of $\Delta \sigma_{v}(t+\Delta t)$ is less than a tolerance (figure 2).

For this model, it is assumed that any external hydraulic gradient is present; car if it is present the effect of associated seepage forces must be considered [10]. The seepage forces have an effect that reduces the effective stress excess and then increases the pore water pressure. Moreover, the selfweight effect is ignored because the thickness of sample is very small, and its weight is neglected comparatively to the vertical applied load.

The global structure of this numerical model can be illustrated by the flow chart shown in figure 2 .

\section{Model Results}

To illustrate different results of this numerical model, the Resedimented Boston Blue clay (BBC) is taken as example; it is characterized by the following properties [10]: Specific gravity of solids $G_{s}=2.80$, liquid limit $L L=47.1$, compression index $c_{c}=0.40$, initial void ratio $e_{0}=1.26$, coefficient of consolidation $c_{v}=5.016 \times 10^{-2} \mathrm{~cm}^{2} / \mathrm{min}$, initial effective stress $\sigma_{v 0}^{\prime}=68.4 \mathrm{kPa}$, initial coefficient of compressibility $a_{v 0}=0.00254 / \mathrm{kPa}$ and initial hydraulic permeability $k_{v o}=5,526 \times 10^{-4} \mathrm{~cm} / \mathrm{min}$.

Different simulations with this model are conducted for test samples with initial height of $H_{o}=25 \mathrm{~mm}$.

The two important results of this numerical model are the vertical load $\Delta \sigma_{v}(t)$ applied at the top boundary of sample, and the excess pore water pressure $\Delta u_{H}(t)$ measured at the bottom of sample during CRS consolidation test. These two parameters are used with others parameters to evaluate the consolidation properties of soils such as compressibility curve, coefficient of consolidation $c_{v}$ and hydraulic conductivity $k_{v}[3,12,19]$.

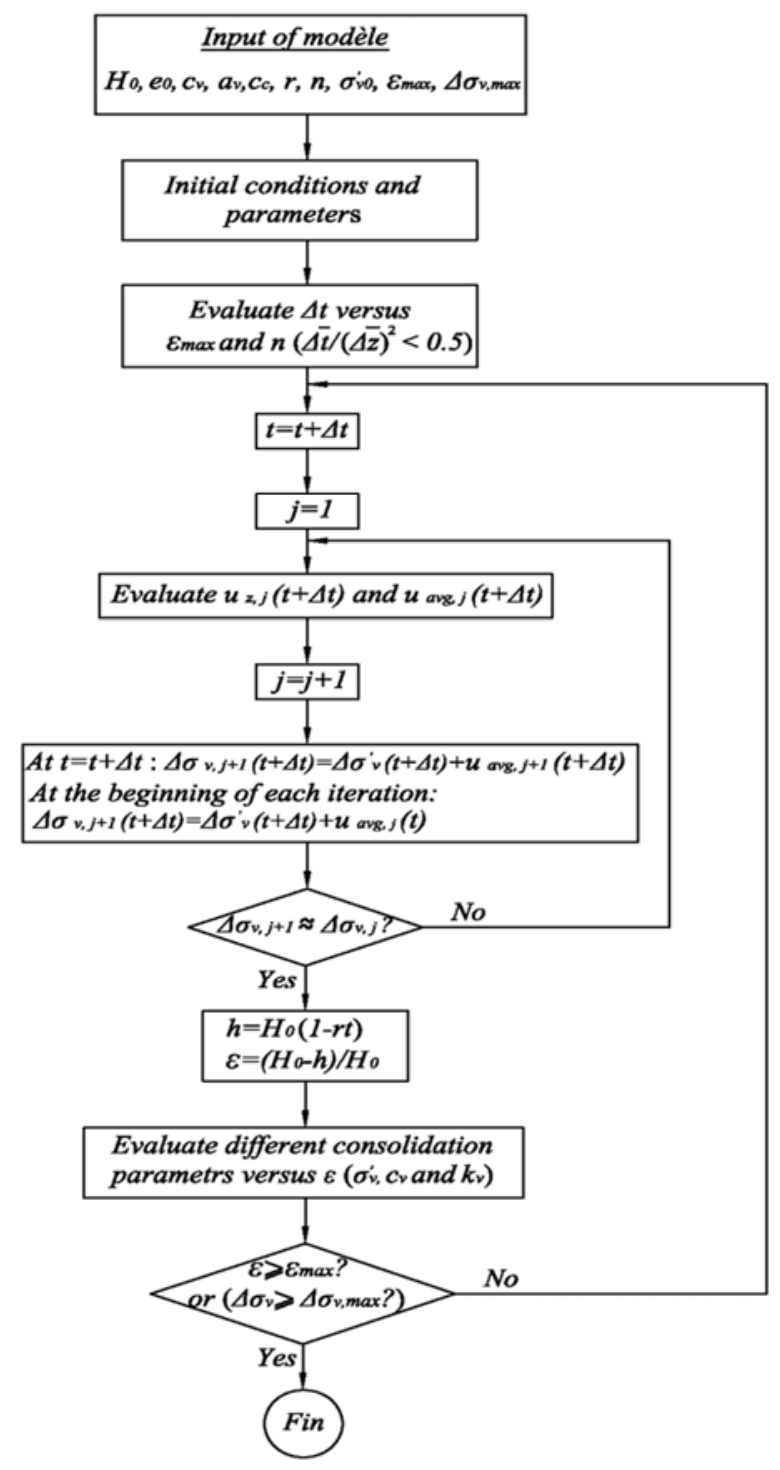

Figure 2. Flow chart resuming global structure of numerical model.

Variations of applied vertical load and base excess pore water pressure, evaluated by this numerical model, versus average strain of soil sample for linear and nonlinear soils, and for three strain rates $(0.1 \% / \mathrm{h}, 1 \% / \mathrm{h}$ and $10 \% / \mathrm{h})$ are presented in figures $3 \mathrm{a}$ and $3 \mathrm{~b}$ respectively. Theses variations indicate that (figure 3 ):

(1) Convergence between linear and nonlinear variations of applied vertical load or base excess pore water pressure is observed only during small stains range.

(2) Applied vertical load increases linearly with strain for linear soils and nonlinearly for nonlinear soils.

(3) Base excess pore pressure increases linearly until reaches a pick and then decreases with strain for linear soils and increases nonlinearly and continuously for nonlinear soils. 
(4) Variations of applied vertical stress or base excess pore pressure have similar trends for all strain rates but with different magnitudes. This indicates that consolidation properties evaluated from CRS test results are strain rate-dependent.

The above results of this numerical model deviate from CRS consolidation theories [3] based on small strain conditions and shows Similar findings with numerical and theoretical methods based on large strain conditions $[5,10]$. For example, the base excess pore pressure for linear soils is assumed to be constant by small strain theories during all duration of CRS test [3], but results of this numerical model indicate that it increases until reaches a pick and then decreases continuously until the end of the test. Furthermore, the use of CRS data of this numerical model to evaluate $c_{v}$ and $k_{v}$ variations by the small and large strain theories, permits to verify which $c_{v}$ and $k_{v}$ values, from small or large strain theories, is closer to the assumed values of $c_{v}$ and $k_{v}$ used to generate CRS data of this model [20].
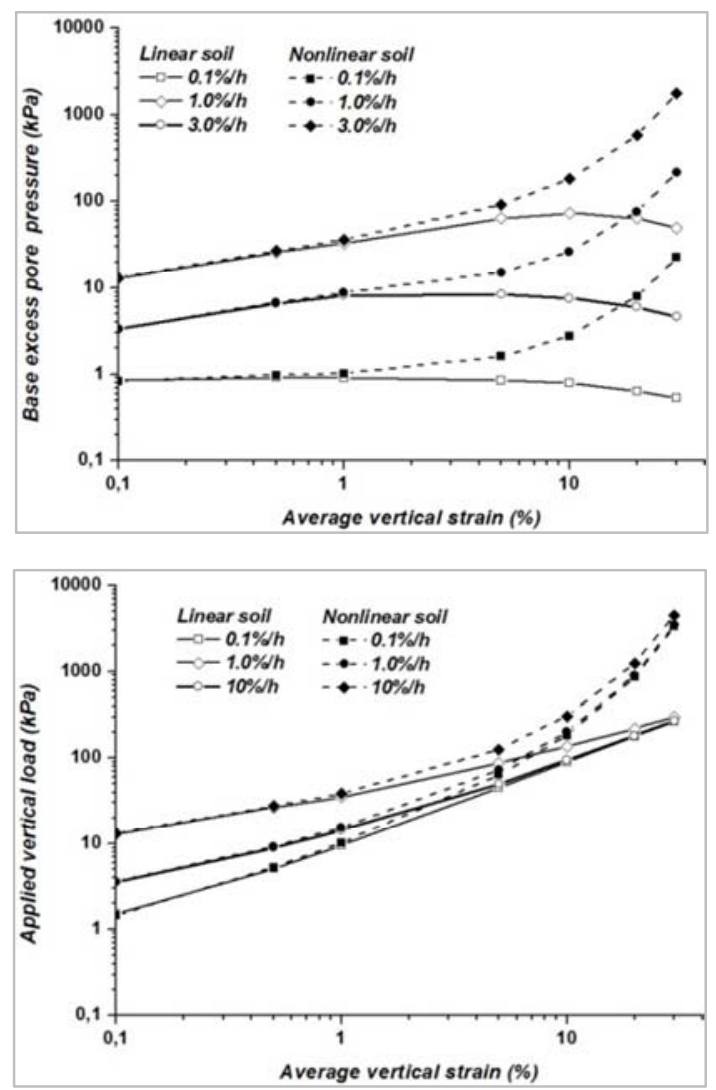

Figure 3. Variations of applied vertical load and base excess pore pressure versus average vertical strain for linear and nonlinear soils (BBC soil).

The small strain theory of Wissa et al [3] assumes in the steady state $\left(T_{v}>0.5\right)$ that the coefficient of consolidation $c_{v}$ and hydraulic permeability $k_{v}$ are defined as

For linear soil:

$$
c_{v}=\frac{H_{0}^{2}\left(\Delta \sigma_{v}(t+\Delta t)-\Delta \sigma_{v}(t)\right)}{2(\Delta t) \Delta u_{H}, a v g}
$$

$$
k_{v}=\frac{\gamma_{w} r H_{0}^{2}}{2 \Delta u_{H}(t)}
$$

For nonlinear soil:

$$
\begin{gathered}
c_{v}=\frac{-H_{0}^{2} \log \left(\sigma_{v}(t+\Delta t) / \sigma_{v}(t)\right)}{2(\Delta t) \log \left(1-\frac{\Delta u_{H, a v g}}{\sigma_{v, a v g}}\right)} \\
k_{v}=\frac{-0.434 \gamma_{w} r H_{0}^{2}}{2 \sigma_{v, a v g}^{\prime} \log \left(1-\frac{\Delta u_{H, a v g}}{\sigma_{v, a v g}}\right)} \\
\sigma_{v}(t)=\sigma_{v 0}^{\prime}+\Delta \sigma_{v}(t)
\end{gathered}
$$

Where : $\Delta \sigma_{v}(t+\Delta t)$ and $\Delta \sigma_{v}(t)$ are the applied vertical load values at times $t+\Delta t$ and $t$ respectively.

$\Delta u_{H}(t)$ is the base excess pore pressure at time $t$.

$\sigma_{v, \text { avg }}$ is the average value of $\sigma_{v}$ over $\Delta t$.

$\Delta u_{H, a v g}$ is the average value of base excess pore pressure over $\Delta t$

$\sigma_{v, \text { avg }}^{\prime}$ is the average value of effective vertical stress over $\Delta t$.

$H_{0}$ is the initial sample height.

$\gamma_{w}$ is the unit weight of water, and $\Delta \mathrm{t}$ is the time step.

The large strain theories of Lee [5] and Sheahan and Watters [12] assume in the steady state $\left(T_{v}>0.5\right)$, that the coefficient of consolidation $c_{v}$ and hydraulic permeability $k_{v}$ are defined as

For linear soil:

$$
\begin{gathered}
c_{v}=\frac{h^{2}\left(\Delta \sigma_{v}(t+\Delta t)-\Delta \sigma_{v}(t)\right)}{2(\Delta t) \Delta u_{H}, a v g} \\
k_{v}=\frac{\gamma_{w} r h^{2}}{2 \Delta u_{H}(t)}
\end{gathered}
$$

For nonlinear soil:

$$
\begin{gathered}
c_{v}=\frac{-h^{2} \log \left(\sigma_{v}(t+\Delta t) / \sigma_{v}(t)\right)}{2(\Delta t) \log \left(1-\frac{\Delta u_{H, a v g}}{\sigma_{v, a v g}}\right)} \\
k_{v}=\frac{-0.434 \gamma_{w} r h^{2}}{2 \sigma_{v, a v g}^{\prime} \log \left(1-\frac{\Delta u_{H, a v g}}{\sigma_{v, a v g}}\right)}
\end{gathered}
$$

Where $h$ is the current specimen height at time $t$.

A dimensionless time factor $T_{v}$ was derived for CRS conditions [12], it indicates the degree of transience in the specimen strain distribution, and is evaluated from a function $F$ that at any time equal to 
For linear soil:

$$
F=1-\frac{\Delta u_{H}(t)}{\Delta \sigma_{v}(t)}
$$

For non linear soil:

$$
F=\frac{\log \left(\sigma_{v}(t)-\Delta u_{H}(t)\right)-\log \sigma_{v 0}^{\prime}}{\log \left(\sigma_{v}(t)\right)-\log \sigma_{v 0}^{\prime}}
$$

For both linear and non linear soils:

$$
T_{v}=4.78(F)^{3}-3.21(F)^{2}+1.63 F+0.0356
$$

The calculated values of $c_{v}$ and $k_{v}$ by using the small and large strain theories for the linear soil case, are plotted versus average strain in figures 4 and $5(\mathrm{a}, \mathrm{b}$ and $\mathrm{c}$ ) for the strain rates of $(0.1 \% / \mathrm{h}, 1 \% / \mathrm{h}$ and $10 \% / \mathrm{h})$ respectively. During the transient state stage $\left(T_{v}<0.5\right)$, high values of $c_{v}$ and $k_{v}$ are obtained by using both small and large strain theories for all strain rates. Then, at the start of steady state stage, a good accuracy is observed between $c_{v}$ and $k_{v}$ values obtained by all methods for the two strain rates of $(0.1 \% / \mathrm{h}$ and $1 \% / \mathrm{h})$. Subsequently, as the strains increase, the $c_{v}$ and $k_{v}$ variations obtained by the large stain theory, closely correspond to the numerical model values for the two strain rates of $(0.1 \% / \mathrm{h}$ and $1 \% / \mathrm{h})$, but the small stain theory overestimates $c_{v}$ and $k_{v}$ values comparatively to the $c_{v}$ and $k_{v}$ model values. For the highest strain rate $(10 \% / \mathrm{h})$, the values of $c_{v}$ and $k_{v}$ estimated by both small and the large strain theories are largely different to the constant values of $c_{v}$ and $k_{v}$ assumed by this model. This deviation is justified by the strain rate effect on the consolidation parameters of CRS consolidation test [20]. Results of this model indicates also that the obtained $c_{v}$ value by using the large strain theory is constant during all steady state duration, which is similar to the Wissa et al assumption [3]. It can be also observed that for the BBC soil case, the strain rate effect on the CRS results is considerable only when the standardized strain rate $\beta=r H_{0}^{2} / c_{v} \geq 0.1$ which is in good agreement with several others recommendations proposed to select proper strain rates for CRS consolidation test $[5,21,22]$. Results of others simulations (not shown) indicate the same trends for the nonlinear soil case.

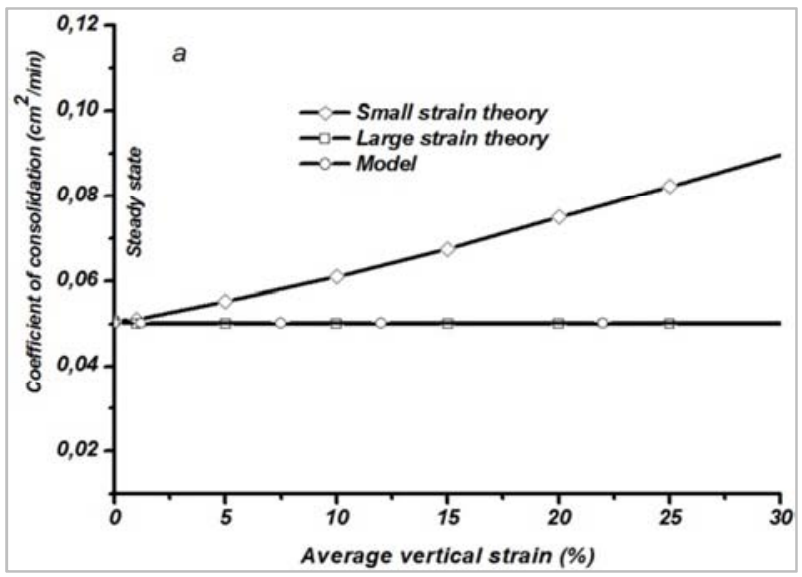

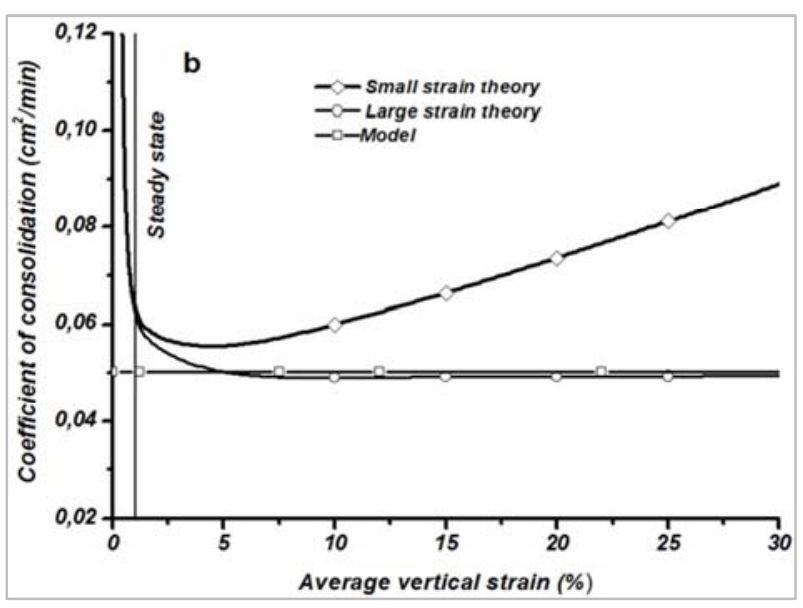

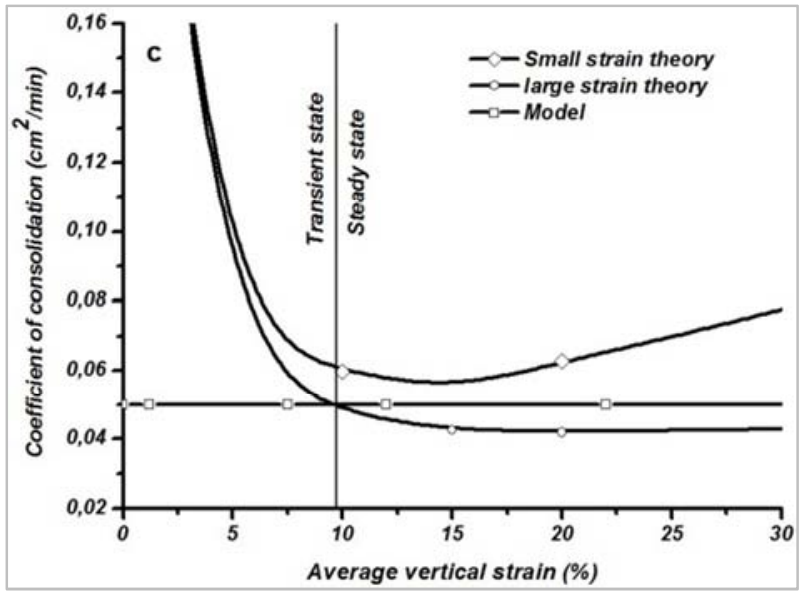

Figures 4. Variations of coefficient of consolidation versus average strain for small and large strain theories: a) $0.1 \% / \mathrm{h}, \mathrm{b}) 1 \% / \mathrm{h}, \mathrm{c}) 10 \% / \mathrm{h}$.

\section{Experimental Verification}

Results of two experimental works $[12,23]$ have been used to check the performance of this numerical model to produce results that are convenient with large strain conditions of CRS consolidation test. Sheahan and Watters (1997) [12] conducted three incremental tests and nine CRS consolidation tests with three different strain rates $(0.1 \% / \mathrm{h}$, $1 \% / \mathrm{h}$ and $3 \% / \mathrm{h}$ ) on resedimented Boston Blue Clay (BBC). Nonlinear theory of CRS consolidation test with larges train conditions (equations. 32 and 33) was used by Sheahan and Watters to interpret the data of CRS tests, and the obtained results were compared with those of incremental consolidation tests. Moreover, T. M. H. Lok and X. Shi (2008) [23] performed incremental and CRS consolidation tests on two types of Macau Marine Clays (MMC), the first is reconstituted and the second is undisturbed. Linear theory of CRS consolidation test with large strain conditions (equations. 30 and 31) was used by T. M. H. Lok and X. Shi to analyze the data of CRS tests. 

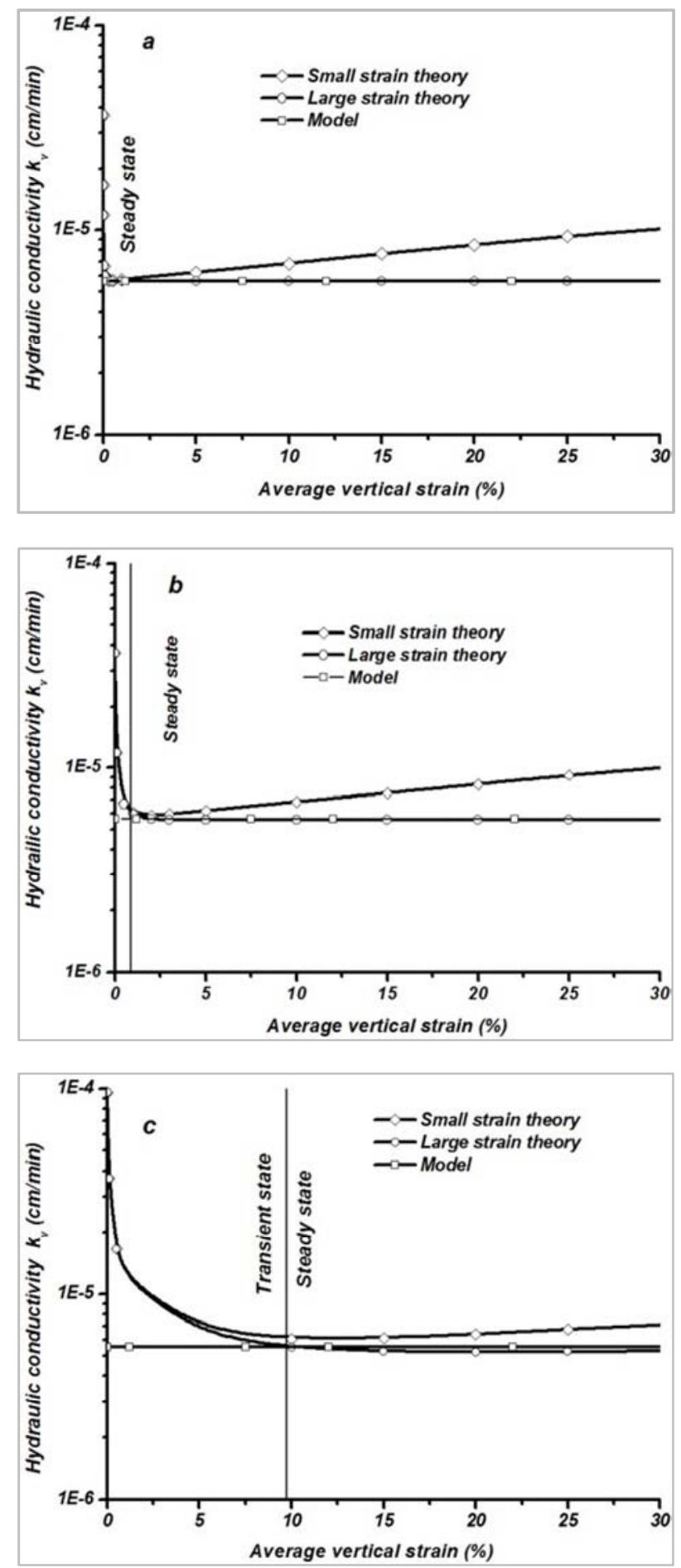

Figures 5. Variations of hydraulic permeability versus average strain for small and large strain theories: a) $0.1 \% / h, b) 1 \% / h, c) 10 \% / h$.

\subsection{Experimental Works of Sheahan and Watters (1997)}

Resedimented BBC was prepared in batches using a process based on methods used at Massachusetts Institute of Technology. Natural BBC passing a sieve no 40 was oven dried and ground into a powder of which $95 \%$ passed the sieve no 100 . The slurry was mixed at an initial water content of $100 \%$. The slurry was then drawn into an evacuated cylindrical chamber $(25.4 \mathrm{~cm}$ diameter, $35 \mathrm{~cm}$ high), which was doubly drained and loaded using a piston. The slurry was incrementally consolidated to a maximum effective stress of $100 \mathrm{kPa}$ and rebounded to a final effective stress of $25 \mathrm{kPa}$. After batch removal from the cylinder, pieces were cut, sized approximately for each test type to be performed (CRS consolidation tests, incremental consolidation tests), coated with a paraffin/petroleum jelly mixture, wrapped in cellophane, and stored in a humid room.

The CRS consolidation tests were performed using a computer-automated, hydraulically loaded Rowe cell [24]. During specimens' saturation phase, back pressure is applied through both the base porous element and the top drainage surface. Pore pressures are measured at five points through the specimen depth: at the top surface; at the specimen base; and at three middle depth points. The maximum effective stress reached during CRS tests varied from 320 to $510 \mathrm{kPa}$, and the final stress levels were maintained for $24 \mathrm{~h}$ to monitor final pore pressure dissipation and secondary compression. For this tests program, no unloading of specimens was performed.

Conventional incremental tests on the same soil were also conducted using procedures recommended in ASTM Standard D2435. The specimens were doubly drained and no back pressure was applied prior to consolidation. A load increment ratio of about 2 was applied, and each load was maintained 3 to $4 \mathrm{~h}$ prior the application of the next loading. Stress-strain results from the IL tests were evaluated based on end of primary states.

Characteristics of BBC soil used to simulate different CRS tests by this numerical model are summarized in table 01 . The values of $H_{0}$ and $e_{0}$ used during each simulation are the averages of three initial height values and three initial void ratio values of each CRS tests type, respectively. The values of $c_{v}, a_{v 0}, c_{c}$ and $\sigma_{v 0}^{\prime}$ are taken from incremental tests results. During simulations, each sample is divided into 100 elements, and BBC soil is first simulated as linear soil ( $a_{v}=$ constant) and then as nonlinear soil ( $c_{c}=$ constant). Subsequently, the obtained simulations data are used to evaluate $c_{v}$ and $k_{v}$ variations by using nonlinear method (equations. 32 and 33).

Table 1. Characteristics used in different simulations of CRS tests (BBC soil).

\begin{tabular}{lllllll}
\hline CRS test type & $\mathbf{H}_{\mathbf{0}}(\mathbf{m m})$ & $\mathbf{R}(\mathbf{\%} / \mathbf{h})$ & $\mathbf{e}_{\mathbf{0}}$ & $\mathbf{c}_{\mathbf{v}}\left(\mathbf{c m}^{2} / \mathbf{m i n}\right)$ & $\sigma_{v 0}^{\prime}(\mathbf{k P a})$ & $\mathbf{a}_{\mathbf{v} 0}(\mathbf{1} / \mathbf{k P a})$ \\
\hline $1 \% / \mathrm{h} \mathrm{CRS} \mathrm{tests}$ & 62.73 & 1.0 & 1.32 & 0.05016 & 68.4 & 0.00183 \\
$3 \% / \mathrm{h}$ CRS tests & 61.26 & 3.0 & 1.30 & 0.05016 & 68.4 & 0.4 \\
\hline
\end{tabular}

For the $1 \% / \mathrm{h}$ CRS tests and during the steady state $\left(T_{v} \geq 0.5\right)$, the $c_{v}$ and $k_{v}$ variations versus average strain of sample, obtained by numerical simulation of CRS tests are very close to the $c_{v}$ and $k_{v}$ experimental variations estimated 
by large strain theories for the linear soil case (figures $6 \mathrm{a}$ and $7 \mathrm{a})$. During the transient state $\left(T_{v}<0.5\right)$, a small deviation is observed between numerical and experimental $k_{v}$ variations (figure 7a).

For the $3 \% / \mathrm{h}$ CRS tests, a good convergence is also obtained between experimental and numerical $c_{v}$ variations estimated by large strain theories for the linear soil case (figure 6b). However, a considerable deviation is observed between experimental and numerical $k_{v}$ variations for both linear and nonlinear soils (figure $7 \mathrm{~b}$ ).
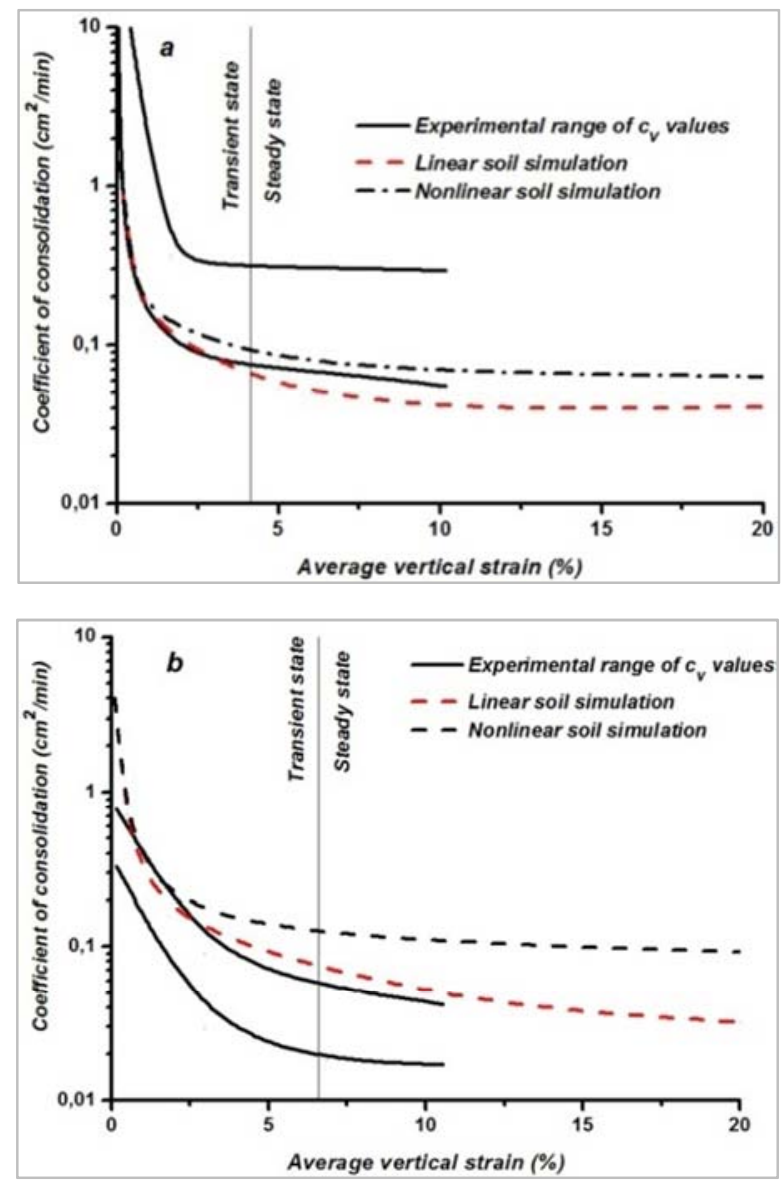

Figures 6. Comparison between numerical and experimental $c_{v}$ variations versus average strain for two strain rates (BBC soil): a) $1 \% / h, b) 3 \% / h$.

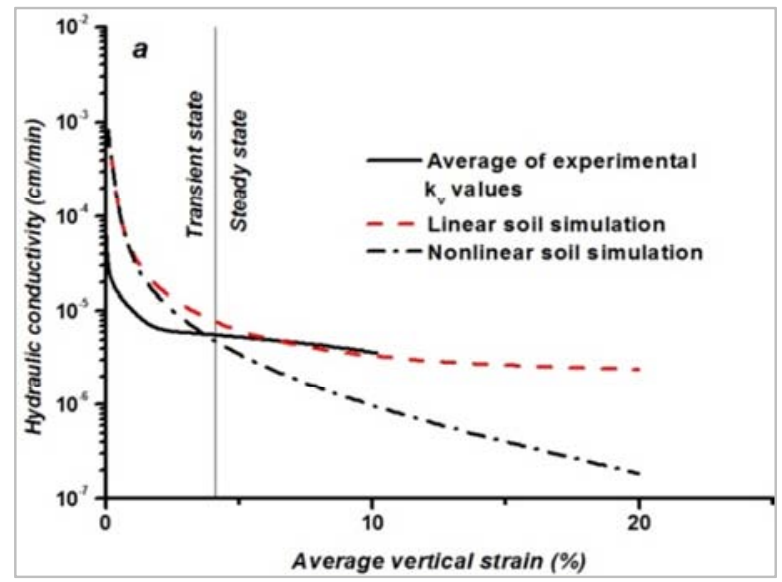

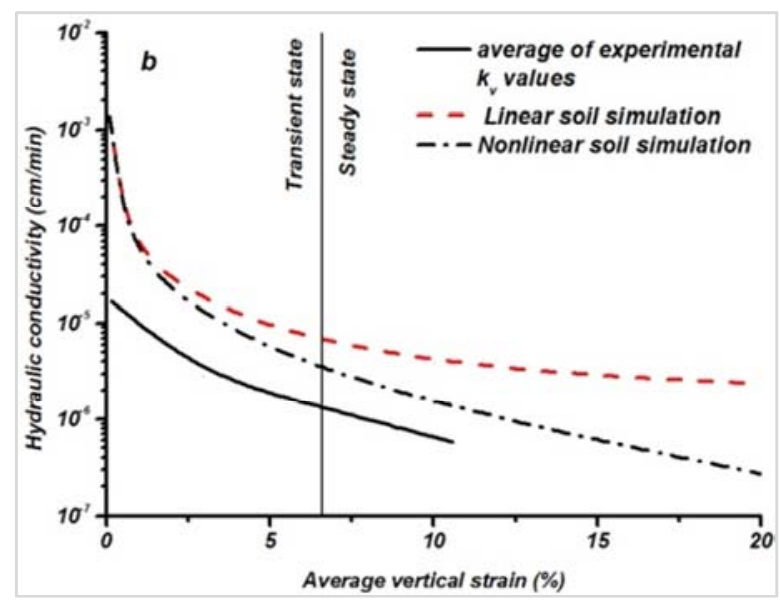

Figures 7. Comparison between numerical and experimental $k_{v}$ variations versus average strain for two strain rates (BBC soil): a) $1 \% / h, b) 3 \% / h$.

\subsection{Experimental Works of T. Lok and X. Shi (2008)}

T. M. H. Lok and X. Shi (2008) [23] performed IL and CRS consolidation tests on two types of Macau Marine Clays (MMC), the first is reconstituted characterized by $L L=65$ and $e_{0}=1.65$, and deformed under a strain rate of $2 \% / \mathrm{h}$ during CRS tests, the second is undisturbed characterized by $L L=60$ and $e_{0}=1.37$, and consolidated using a strain rate of $1 \% / \mathrm{h}$ during CRS tests.

A consolidometer was used to prepare the reconstituted samples. The material necessary to prepare the reconstituted samples was taken from an excavation site in Macau, and was then mixed into thick slurry and passed through $600 \mu \mathrm{m}$ standard sieve to remove all large soil particles and shells. The slurry was poured into the consolidometer for consolidation, and a pressure of 1 bar was applied to the slurry from the bottom cap. The consolidation was stopped when the primary consolidation phase had finished. After finishing the consolidation, the sample was carefully pushed out by hydraulic extruder and was cut into different sizes depending on the tests to be performed. The peripheral part of the specimen was discarded because of disturbance.

Two different sizes of undisturbed samples were obtained with $76 \mathrm{~mm}$ stainless steel Shelby piston tube sampler and U100 steel tube sampler with the length of $1 \mathrm{~m}$ and $0.5 \mathrm{~m}$, respectively. The undisturbed clay samples were taken at the depth of $3 \mathrm{~m}$ to $6 \mathrm{~m}$ from the first site (Taipa), and at the depth of $6 \mathrm{~m}$ to $13 \mathrm{~m}$ from the second site (Cotai). After the sample was taken out from the bore-hole, both ends of the sample tube were sealed with wax in the field.

In incremental tests, the cell of $75 \mathrm{~mm}$ in diameter was used to explore the consolidation behavior of reconstituted samples; while the cell of $50 \mathrm{~mm}$ in diameter was used to explore the behavior of undisturbed samples. Both cells have the height of $20 \mathrm{~mm}$. Each load increment is maintained constant for 24 hours, and the load was doubled for the next increment. During the consolidation process, the vertical displacements were recorded at time intervals of $0,0.1,0.25$, $0.5,1,2,4,8,15,30,60,120,240,480,720,1440$ minutes after the application of each load increment. 
In CRS tests, during saturation phase a back pressure of $200 \mathrm{kPa}$ was applied at both sides of specimens having $20 \mathrm{~mm}$ height. Three CRS tests were performed, two with a strain rate of $2 \% / \mathrm{h}$ and one with a strain rate of $1 \% / \mathrm{h}$. Characteristics of MMC soil used to simulate different CRS tests by this numerical model are summarized in table 02 .
The values of $c_{v}, a_{v 0}, c_{c}$ and $\sigma_{v 0}^{\prime}$ are also taken from incremental tests results. MMC soil is simulated as linear soil and then as nonlinear soil. The $c_{v}$ and $k_{v}$ variations are evaluated by using linear method (equations. 30 and 31). Each sample is divided into 100 elements during different numerical simulations.

Table 2. Characteristics used in different simulations of CRS tests (MMC soil).

\begin{tabular}{llllllll}
\hline Soiltypes & $\mathbf{H}_{\mathbf{0}}(\mathbf{m m})$ & $\mathbf{r}(\mathbf{\%} / \mathbf{h})$ & $\mathbf{e}_{\mathbf{0}}$ & $\mathbf{c}_{\mathbf{v}}\left(\mathbf{c m}^{2} / \mathbf{m i n}\right)$ & $\sigma_{v 0}^{\prime}(\mathbf{k P a})$ & $\mathbf{c}_{\mathbf{c}}$ & $\mathbf{a}_{\mathbf{v} \mathbf{0}}(\mathbf{1} / \mathbf{k P a})$ \\
\hline Reconstituted samples (RMMC) & 20 & 2.0 & 1.65 & 0.0320 & 56 & 0.47 & 0.0036 \\
Undisturbed samples (UMMC) & 20 & 1.0 & 1.37 & 0.0335 & 65 & 0.30 & 0.0020 \\
\hline
\end{tabular}

For RMMC, a good convergence is observed for the case of nonlinear soil between $c_{v}$ and $k_{v}$ variations obtained by this numerical model and experimental variations of $c_{v}$ and $k_{v}$ evaluated by large strain theories of CRS consolidation test, with a small deviation of $c_{v}$ variations at the start of steady state (figures $8 \mathrm{a}$ and $8 \mathrm{~b}$ ).
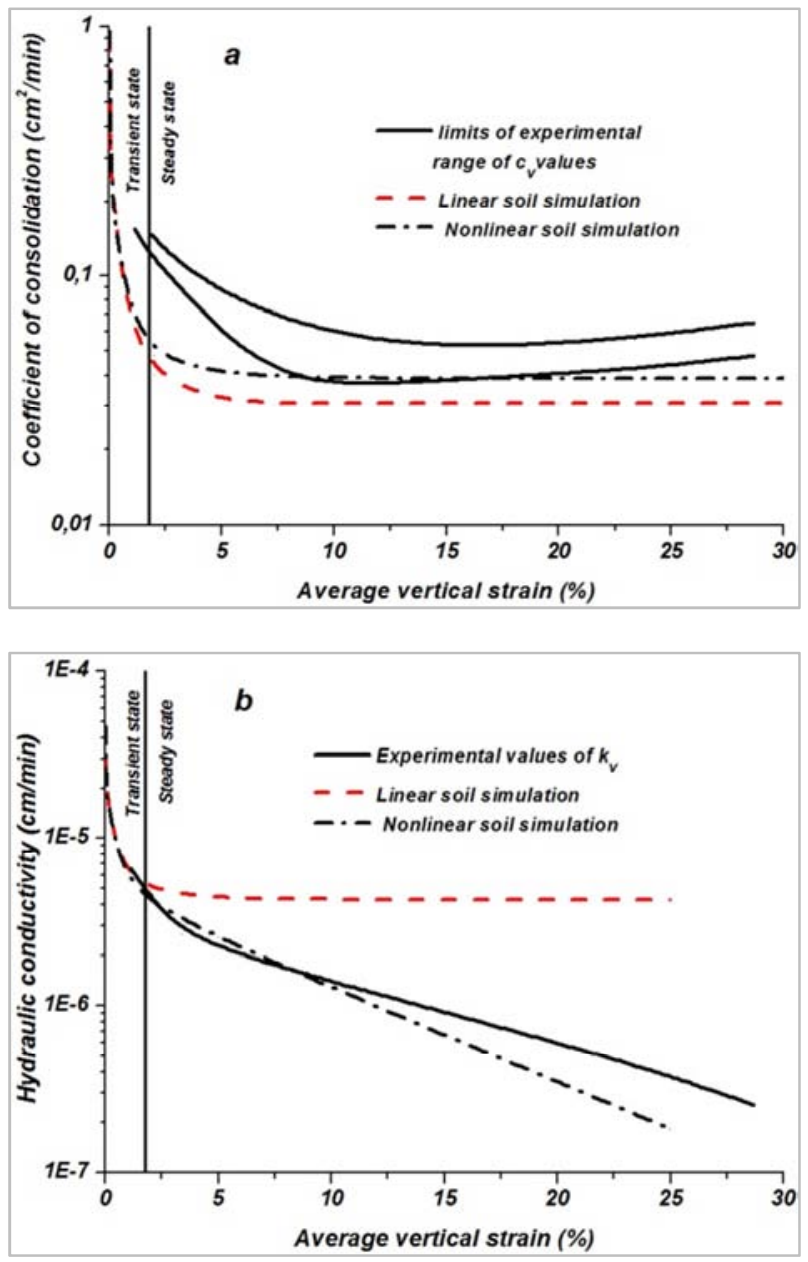

Figures 8. Comparison between numerical and experimental variations versus average strain for RMMC soil of: a) $c_{v}$, b) $k_{v}$.

For UMMC, a small deviation is also obtained between experimental and numerical variations of $c_{v}$ and $k_{v}$, but generally no significant difference is observed especially for nonlinear soil (figures 9a and 9b).
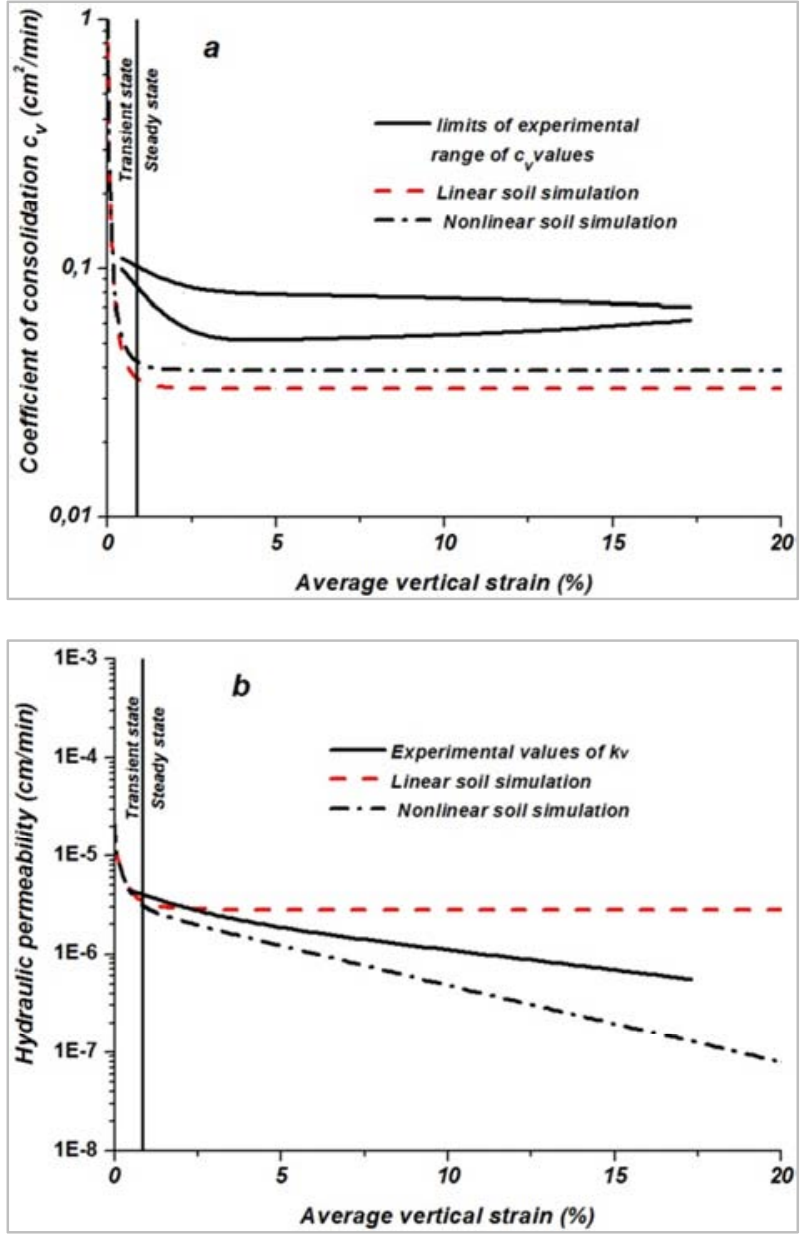

Figures 9. Comparison between numerical and experimental variations versus average strain for UMMC soil of: a) $c_{v}$, b) $k_{v}$.

Finally, from different comparisons it is observed that the results of numerical simulation of BBC linear soil are close to the experimental results than $\mathrm{BBC}$ nonlinear soil car probably the $\mathrm{BBC}$ soil has a linear behavior. Furthermore, because the numerical simulation of nonlinear soil of MMC provided results that more nearer to the experimental results than the linear soil, the MMC soil has probably a nonlinear behavior. Subsequently, choose of congruent method for analyzing linear or nonlinear soil is an important phase for interpreting the CRS tests [20]. 


\section{Conclusions}

In this study, the Terzaghi's numerical solution with finite differences approach of consolidation for constant loading is used to develop a new numerical model that simulates iteratively the continuous loading of CRS consolidation test. Results of this numerical model lead to the following:

1) Use of variable height of sample during CRS consolidation in this numerical model permits to get results (applied vertical stress and base excess pore pressure) that converge to analytical and numerical results based on large strain conditions.

2) Variations of coefficient of consolidation $c_{v}$ and hydraulic permeability $k_{v}$ estimated by the large strain theories from numerical model data, are very close to those corresponding to the model results. The small strain theory overestimates $c_{v}$ and $k_{v}$ with comparison to the model results.

3) Variation of coefficient of consolidation $c_{v}$ estimated by large strain theories with this numerical model, is constant during the steady state stage of CRS test which is convenient with assumptions of CRS consolidation theories.

4) Simulation of some experimental CRS consolidation tests by using this numerical model provides results $\left(c_{v}\right.$ and $k_{v}$ ) that comparable with experimental values.

5) To get reliable results, it's important to select an appropriate method (linear or nonlinear) during interpreting CRS consolidation test data.

\section{References}

[1] J. J. Hamilton and C. B. Crawford, "Improved determination of preconsolidation pressure of a sensitive clay," Papers on Soils, ASTM STP 254, Committee D-18, Eds, ASTM International, West Conshohocken, PA, pp. 254-270, 1959.

[2] R. E. Smith and H. E. Wahls, "Consolidation under constant rate of strain," Journal of the Soil Mechanics and Foundations Division, ASCE95 (SM2), pp. 519-539, 1969.

[3] A. E. Z. Wissa, J. T. Christian, E. H. Davis, S. Heiberg, "Consolidation at constant rate of strain," Journal of the Soil Mechanics and Foundations Division, ASCE97(10), pp. 13931413. 1971.

[4] Y. Umehara and K. Zen, "Constant rate of strain consolidation for very soft clayey soils," Soil Found. 20(2), pp. 79-95. 1980.

[5] K. Lee, "Consolidation With Constant Rate of Deformation," Geotechnique, 31(2), 215-229. 1981.

[6] D. Znidarcic, R. L. Schiffman, V. Pane, P. Croce, H. Y. Ko, H. W. Olsen, "The theory of one-dimensional consolidation of saturated clays: Part V. Constant rate of deformation test in grand analysis," Geotechnique, 36(2), 227-237. 1986.

[7] S. Leroueil, M. Kabbaj, F. Tavenas, R. Bouchard, "StressStrain-Strain Rate Relation for the Compressibility of Sensitive Natural Clays," Geotechnique, 35(2), 159-180. 1985.

[8] K. M. Sample and C. D. Shackelford, "Apparatus for Constant Rate-Of-Strain Consolidation of Slurry Mixed Soils," Geotech.
Test. J., 35(3), 409-419. 2012.

[9] J. Rui, C. Jinchun, H. Takenori, "Interpretation of coefficient of consolidation from CRS test results," Geomechanics and Engineering, 5(1), 57-70. 2013.

[10] H. Pu, P. J. Fox, Y. Liu, "Model for Large Strain Consolidation Under Constant Rate of Strain," International Journal for Numerical and Analytical Methods in Geomechanics, 37(11), 1574-1590. 2013.

[11] Y. P. Vaid, P. K. Robertson, R. G. Campanella, "Strain rate behavior of Saint-Jean-Vianney clay," Canadian Geotechnical Journal, 16(1), 34-42. 1979.

[12] T. C. Sheahan, P. J. Watters, "Experimental Verification of CRS Consolidation Theory," Journal of Geotechnical and Geoenvironmental Engineering, 123(5), 430-437. 1997.

[13] T. Moriwaki, T. Satoh, "Method for determining the horizontal coefficient of permeability of clay," Proceedings of the $44^{\text {th }}$ Annual Presentation of Geotechnical Engineering, Yokohama, Japan, 219-220. 2009. (In Japanese).

[14] A. L. Adams, "Laboratory Evaluation of the Constant Rate of Strain and Constant Head Techniques for Measurement of the Hydraulic Conductivity of Fine Grained Soils," M. S. thesis, Massachusetts Institute of Technology, Cambridge, MA. 2011.

[15] K. A. Kassim, S. A. R. Ahmad, B. H. K. Ahmad, S. Y. Chong, C. S. Lam, "Criteria of Acceptance for Constant Rate of Strain Consolidation Test for Tropical Cohesive Soil," Geotechnical and Geological Engineering, 34(4), pp. 931-947. 2016.

[16] H .Ahmadi, H. Rahimi, A. Soroush, A. Claes, "Experimental research on variation of pore water pressure in constant rate of strain consolidation test," Acta geotechnical slovenica 2, pp. 47-57. 2014.

[17] C. T. Gorman, T. C. Hopkins, R. C. Deen, V. P. Drnevich, "Constant Rate of Strain and Controlled Gradient Consolidation Testing", Geotechnical Testing Journal, 1 (1), pp. 3-15. 1978.

[18] B. M. Das, "Advanced Soil Mechanics," $3^{\text {th }}$ Edition. Taylor and Francis, London and NewYork, 300-310. 2008.

[19] ASTM, "Standard test method for one-dimensional consolidation properties of saturated cohesive soils using controlled-strain loading," D4186-06, West Conshohocken, PA. 2006.

[20] P. J. Fox, H. Pu, J. T. Christian, "Evaluation of Data Analysis Methods for the CRS Consolidation Test," ASCE Journal of Geotechnical and Geoenvironmental Engineering, 140(6), 04014020-(1-11). 2014.

[21] K. Lee, V. Choa, S. H. Lee, S. H. Quek, "Constant rate of strain consolidation of Singapore Marine Clay," Geotechnique 43(3), 471-488. 1993.

[22] P. Hefu, J. F. Patrick, "Numerical Investigation of Strain Rate Effect for CRS Consolidation of Normally Consolidated Soil," Geotechnical Testing Journal. 39(1), 80-90. 2016.

[23] T. M. H. Lok and X. Shi, "Consolidation and strength Properties of Macau Marine Clay," Faculty of science and technology, university of Macau. 2008.

[24] B. W. Rowe, L. Barden, "A new consolidation cell," Geotechnique, 16(1), 162-170. 1966. 